\title{
Influence of Tissue Paper Converting Conditions on Finished Product Softness
}

\author{
António de Oliveira Mendes, ${ }^{\mathrm{a}, *}$ Joana Costa Vieira, ${ }^{\mathrm{a}}$ Ana Margarida Carta, ${ }^{\mathrm{b}}$ \\ Enrico Galli, ${ }^{\mathrm{c}}$ Rogério Simões, ${ }^{\mathrm{a}}$ Manuel José dos Santos Silva, ${ }^{\mathrm{a}}$ Ana Paula \\ Costa, ${ }^{\mathrm{a}}$ and Paulo Torrão Fiadeiro ${ }^{\mathrm{a}}$
}

\begin{abstract}
Tissue paper conversion consists of the transformation of base tissue papers into finished tissue products to meet specific demands. When base tissue paper arrives at the converting line, it already holds different requirements that were met during its manufacture in the paper machine (e.g., grammage, bulk, tensile index, etc.). However, what happens during converting can still influence the performance and quality of the finished products. The current work addresses this topic and aims to evaluate the influence of converting conditions on the final softness. For that, two 5-ply finished tissue products were analyzed using different methodologies for their proper characterization in terms of softness and surface analysis. The analyzed products are composed by the same base tissue papers, but some changes were applied on their settings in the converting line. In particular, the base tissue papers arrangement and the embossing pressure affected the finished products, resulting in one of them being softer and more pleasant to touch, with a global handfeel (HF) value of 75.3 units, and the other revealed to be rougher and less pleasant, with a global handfeel (HF) value of 68.0 units.
\end{abstract}

Keywords: Tissue paper; Converting conditions; Finished product; Softness; Handfeel; Image Analysis

Contact information: a: Fiber Materials and Environmental Technologies (FibEnTech-UBI), Universidade da Beira Interior, R. Marquês D'Ávila e Bolama, 6201-001 Covilhã, Portugal; b: Instituto de Investigação da Floresta e Papel (RAIZ), Quinta de S. Francisco, Rua José Estevão (EN 230-1), 3800-783 Eixo, Aveiro, Portugal; c: The Navigator Company, R. Bombeiros da Celulose, 3800-536 Cacia, Portugal;

*Corresponding author: ant.mendes@ubi.pt

\section{INTRODUCTION}

Tissue is a special and unique type of paper, as its most important use is in hygiene daily routines. Examples of tissue products include bathroom tissue, kitchen towels, industrial wipes, table napkins, facial tissue, and many others (Kimari 2000). Commonly, tissue is very well distinguished from other paper grades, due to its low grammage, typically lower than $25 \mathrm{~g} / \mathrm{m}^{2}$ according to Hollmark (1983), and because of its creped structure, yielding a rather distinctive surface (Hollmark 1983; Abbott and Schnabel 2000; Kimari 2000; Ramasubramanian and Shmagin 2000; Ho et al. 2007; Gigac and Fišerová 2008; Ramasubramanian et al. 2011; Raunio and Ritala 2012; Boudreau and Germgård 2014; Anukul et al. 2015).

Depending on product end use, specific characteristics are targeted to achieve the desired requirements. In this sense, a wide variety of products exist with specific features for different applications. Examples include products designed to have extra-absorption, extra-resistance, or extra-softness (Kimari 2000; de Assis et al. 2018a).

Concerning bathroom tissue, a subcategory in which toilet papers are included, 
softness is a key feature for consumers (Hollmark 1983; Abbott and Schnabel 2000; Kimari 2000; Furman et al. 2007; de Assis et al. 2018a). A paper that does not meet a certain level of softness, by being too rough or unpleasant to touch, may be rejected and replaced by others. Therefore, the proper assessment of softness is of the utmost importance in this category.

During production, many aspects influence tissue paper softness, such as the type of fibers, refining additives used, creping process, and converting process (Kimari 2000; Ramasubramanian and Shmagin 2000; Ho et al. 2007; Gigac and Fišerová 2008; Ramasubramanian et al. 2011; Raunio and Ritala 2012; Boudreau and Germgård 2014; Rosen et al. 2014; Anukul et al. 2015; de Assis et al. 2018a; de Assis et al. 2018b; Raunio et al. 2018; Spina and Cavalcante 2018). This last aspect consists of a series of operations, such as unwinding, embossing, printing, perforating, rewinding, cutting and packaging, as shown in Fig. 1, performed on base tissue paper sheets to form a multilayer finished product, ready to be placed into the market (Kimari 2000; Vieira et al. 2020).

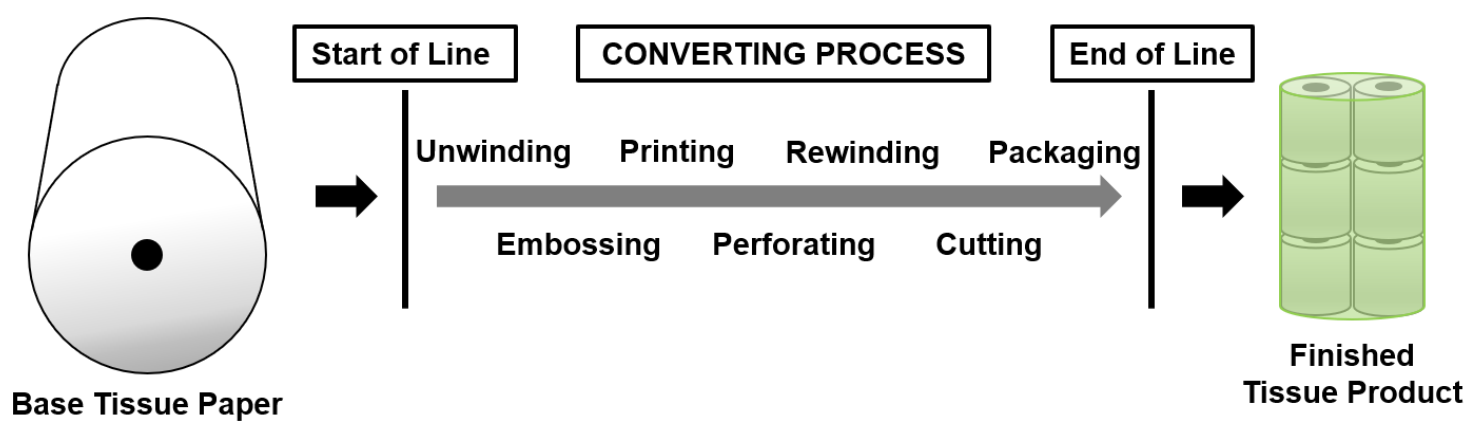

Fig. 1. Converting process operations performed on base tissue paper to obtain the finished tissue product

As already stated, before entering the converting process, the base tissue paper bears specific requirements, and the finished products will depend on these requirements. However, in the converting line, the performance and quality of the finished products may still be altered, depending on the applied converting conditions.

The current work is focused on this topic. Specifically, two commercial toilet tissue products composed of the same base tissue papers were made with changes on the settings in the converting line. All other aspects of base paper manufacture were the same. The main goal was to identify differences in both finished products in terms of softness, caused by their different converting conditions. The product characterization was carried out using two different methodologies.

\section{EXPERIMENTAL}

\section{Materials}

Two commercial toilet tissue products, identified as P2T and P3T, were collected in a factory line and used as the objects of this study. These products were formed using 2 different mother-reels, from which some samples were also collected. One of the motherreels, identified as M2, was a 2-ply arrangement of a base tissue paper, whereas the other mother-reel, identified as M3 was a 3-ply arrangement of a different base tissue paper. These two base tissue papers were produced using mixtures of $85 \%$ hardwood eucalyptus 
and $15 \%$ softwood pine and spruce European bleached kraft pulps. Although M2 and M3 were produced in different paper machines, both mother-reels have the same composition described above, with each tissue sheet having approximately the same grammage, 15 to $16 \mathrm{~g} / \mathrm{m}^{2}$ (ISO 12625-6 2005), and thickness, 110 to $116 \mu \mathrm{m}$ (ISO 12625-3 2014).

Regarding the two finished products, the first P2T was converted having M2 on top and M3 on the bottom, whereas the second product P3T was converted having M3 on top and M2 on the bottom, as shown in Fig. 2. Overall, both commercial products P2T and P3T are 5-ply, with an inversion of the arrangement of the mother-reels defined at the start line of converting, in the unwinding step.

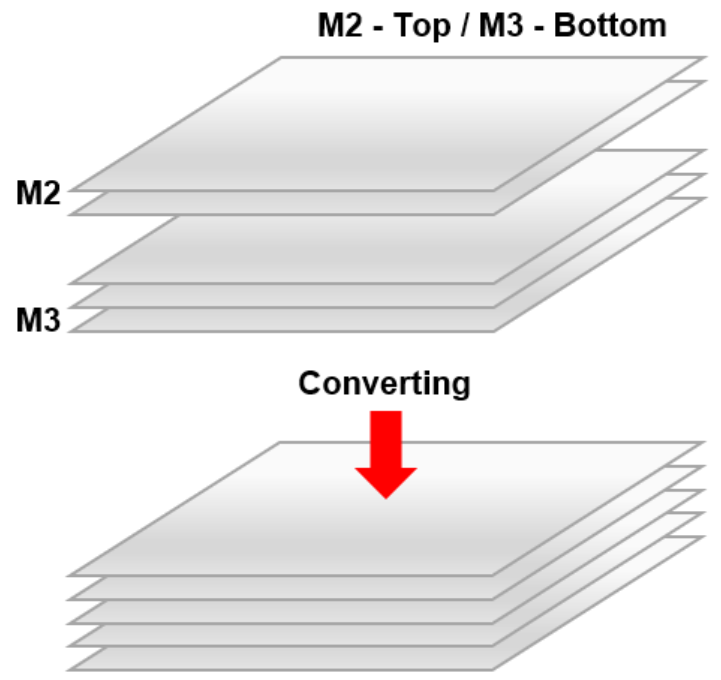

Finished Product P2T

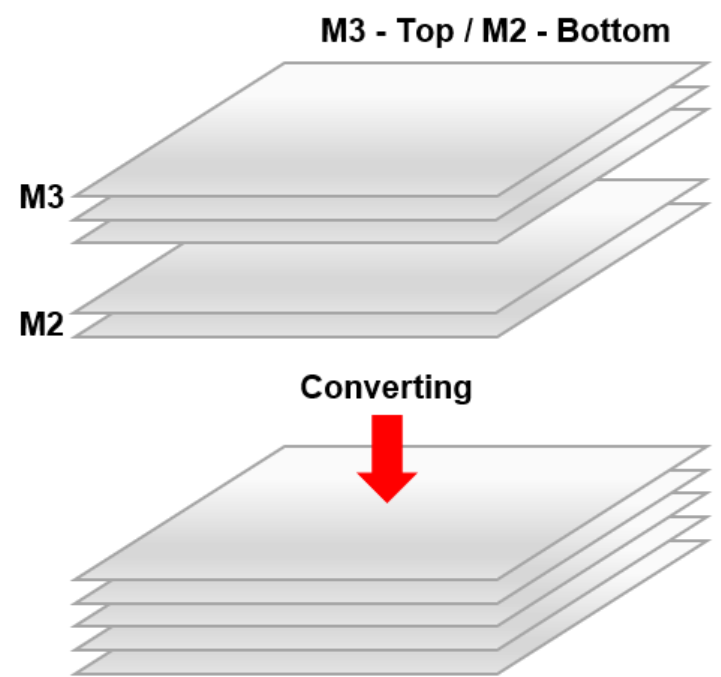

Finished Product P3T

Fig. 2. Mother-reels arrangement in the converting of the 2 finished products P2T and P3T
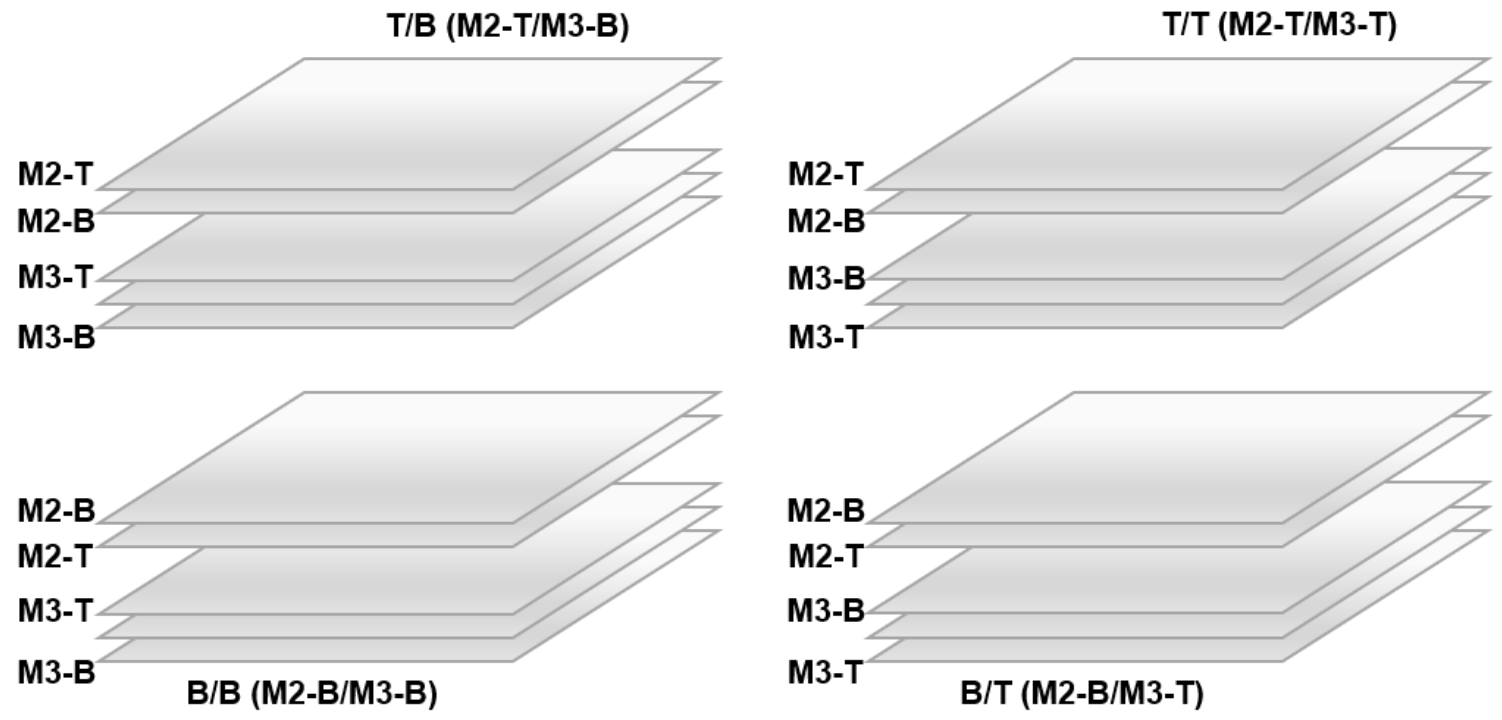

Fig. 3. The 4 tested assembled configurations $T / B, T / T, B / B$, and $B / T$ using the mother-reels $M 2$ and $\mathrm{M} 3$ without passing through the converting line 
It is also noteworthy that products $\mathrm{P} 2 \mathrm{~T}$ and $\mathrm{P} 3 \mathrm{~T}$ consist of finished toilet tissue products, meaning that the samples of these commercial products were collected at the end of the factory converting line. However, the base tissue papers of the mother-reels M2 and M3 were completely free of any operation, as the corresponding samples of these 2 motherreels were collected at the start of the factory converting line. Both mother-reels M2 and M3 were also assembled to create samples of all the 4 possible combinations used for production of $\mathrm{P} 2 \mathrm{~T}$ and $\mathrm{P} 3 \mathrm{~T}$. In particular, they were simply stacked without adhesive nor any other operation conducted on them, respectively, top with bottom (configuration T/B), top with top (configuration $\mathrm{T} / \mathrm{T}$ ), bottom with bottom (configuration $\mathrm{B} / \mathrm{B}$ ), and finally bottom with top (configuration $\mathrm{B} / \mathrm{T}$ ), as shown in Fig. 3. These configurations were assembled to analyze if the top and bottom surfaces of the mother-reels M2 and M3, being oriented inwards or outwards in the final configurations, affect the softness results.

As a general experimental procedure rule, 10 samples of each product and of each of the 4 assembled configurations using the mother-reels were conveniently prepared according to the proper dimensions required for each equipment to be used for their characterization. Normally, from these samples, 5 were used to analyze the top surface, while the other 5 were used for analysis of the bottom surface. The results of the performed essays were expressed in terms of mean and standard deviation for the top and bottom surfaces, and in global.

\section{Methods}

Several experiments were conducted for analysis of the softness and surface properties of the samples collected and prepared for the products $\mathrm{P} 2 \mathrm{~T}$ and $\mathrm{P} 3 \mathrm{~T}$ and for the assembled configurations T/B, T/T, B/B, and B/T. There are many different approaches for the evaluation and assessment of these properties (Hollmark 1983; Rust et al. 1994; Hollmark and Ampulski 2004; Furman et al. 2007; Lima et al. 2009; Ruiz et al. 2010; Rosen et al. 2014; Rastogi et al. 2017; de Assis et al. 2018a; Ko et al. 2018; Perng et al. 2019; Wang et al. 2019). Based on those studies, two different methodologies were followed in the current work. The tissue softness analyzer (TSA) from Emtec Electronic $\mathrm{GmbH}$ (Leipzig, Germany), laboratory equipment, which is used in the tissue paper sector for quality control purposes, was used to perform the measurements of softness. The TSA works by simulating the sensation of the fingertips by touching the tissue samples with vertical lamella, fixed in a rotating disk, under a defined load and rotation speed. The vibrations generated during the rotation are detected by the equipment and are then processed to provide information about the samples. After this first measurement, a vertical displacement of the samples is also realized. Then, all the measured parameters, namely, the real softness (TS7), the felt smoothness/roughness (TS750), and the stiffness (D) are computed through specific algorithms to obtain a global quantification of handfeel (HF) of the analyzed samples (EMTEC Innovative Testing Solutions 2018).

A customized optical system previously used in research for other purposes was also considered for observation of the samples surfaces using specific magnifications and illumination conditions (Mendes et al. 2013, 2014, 2015). First, a tissue paper sample is fixed in a proper holder connected to a motorized XY motion stage, allowing the movement of the sample in both horizontal and vertical directions and for the scan of the sample across its entire area. The sample is observed from both sides (top and bottom surfaces) by two different image detectors. The registered images were set with a field of view of $\approx 10 \times 10$ $\mathrm{mm}^{2}$, a resolution of $1024 \times 1024$ pixels, a bit depth of 10 bits (1024 gray levels), a gain of 1024 arbitrary units, and an exposure time of 6 milliseconds. The magnification used in 
the system is controlled by two macro-objectives, making it possible to observe both surfaces of the sample with specific magnifications, depending on the application in use and of the required level of detail. Finally, the sample can be illuminated from only one side, from the other side, or from both sides through use of two LED light sources. These conditions were used to optimize the system for a convenient and correct observation of the samples in analysis. All the elements of the system are connected to several hardware control units and to a computer, being operated through a graphical user interface software application implemented using the MATLAB ${ }^{\circledR}$ programming language and the Toolboxes for Image Acquisition and Image Processing (Mendes et al. 2013, 2014, 2015).

Three experiments (A, B, and C) were performed in this work with the presented methods. Experiments A and B were focused on the TSA measurements, TS7, TS750, D and HF, this last calculated using the algorithm TPII of the equipment, to evaluate products $\mathrm{P} 2 \mathrm{~T}$ and $\mathrm{P} 3 \mathrm{~T}$ and the different assembled configurations $\mathrm{T} / \mathrm{B}, \mathrm{T} / \mathrm{T}, \mathrm{B} / \mathrm{B}$, and $\mathrm{B} / \mathrm{T}$. Experiment $\mathrm{C}$ was focused on the visualization of the samples surfaces with the customized optical system.

\section{RESULTS AND DISCUSSION}

\section{Experiment A - TSA Measurements of the Products P2T and P3T}

Table 1 contains the HF results for the products P2T and P3T, obtained using the TSA (EMTEC Innovative Testing Solutions 2018).

Table 1. HF for the 2 End-use Products P2T and P3T

\begin{tabular}{|c|c|c|c|}
\hline Product & Top Surface HF & Bottom Surface HF & Global HF \\
\hline P2T & $75.5 \pm 1.5$ & $75.1 \pm 2.0$ & $75.3 \pm 1.7$ \\
\hline P3T & $73.2 \pm 1.4$ & $62.9 \pm 2.6$ & $68.0 \pm 5.8$ \\
\hline
\end{tabular}

Note: Values shown are the mean \pm standard deviation

Considering the top surface of P2T and P3T, similar values of HF are shown for both cases. However, the case differed considerably for the bottom surface of each paper. For the product P3T, a value of 62.9 HF units was obtained, which is a large drop compared to its top surface (difference of $10.3 \mathrm{HF}$ units) and compared to the bottom surface of P2T (difference of 12.2 HF units).

In terms of global results, the product P2T has a HF of 75.3 units, whereas the product $\mathrm{P} 3 \mathrm{~T}$ has a HF of 68.0 units. The global HF standard deviation of the product P3T is also very different and the highest, which is caused by the difference noted in the HF results between the top and bottom surfaces of the product.

These results raise a question. What happened in product P3T, more specifically on its bottom surface? Both products $\mathrm{P} 2 \mathrm{~T}$ and $\mathrm{P} 3 \mathrm{~T}$ are composed by the same mother-reels but with inverted arrangements. Was this the cause that led to a HF decrease in P3T comparatively to P2T, or something else? To further explore this question, let us consider the caliper (thickness), grammage and the remaining parameters measured by the TSA (Table 2). 
Table 2. Caliper, Grammage, TS7, TS750 and D for the 2 End-use Products P2T and P3T

\begin{tabular}{|c|c|c|c|c|c|c|}
\hline Product & Surface & Caliper $(\boldsymbol{\mu m})$ & $\begin{array}{c}\text { Grammage } \\
\left(\mathbf{g} / \mathbf{m}^{\mathbf{2}}\right)\end{array}$ & TS7 & TS750 & $\boldsymbol{D}(\mathbf{m m} / \mathbf{N})$ \\
\hline \multirow{3}{*}{ P2T } & Top & - & - & $14.1 \pm 0.9$ & $61.2 \pm 7.2$ & $1.7 \pm 0.0$ \\
\cline { 2 - 7 } & Bottom & - & - & $14.7 \pm 0.9$ & $50.4 \pm 7.1$ & $1.7 \pm 0.0$ \\
\cline { 2 - 7 } & Global & $695 \pm 14$ & $76.4 \pm 0.5$ & $14.4 \pm 0.9$ & $55.8 \pm 8.8$ & $1.7 \pm 0.0$ \\
\hline \multirow{3}{*}{ P3T } & Top & - & - & $15.2 \pm 0.7$ & $70.2 \pm 5.4$ & $1.8 \pm 0.1$ \\
\cline { 2 - 7 } & Bottom & - & - & $19.4 \pm 1.1$ & $123.4 \pm 26.2$ & $1.8 \pm 0.1$ \\
\cline { 2 - 7 } & Global & $725 \pm 16$ & $76.0 \pm 0.2$ & $17.3 \pm 2.4$ & $96.8 \pm 33.2$ & $1.8 \pm 0.1$ \\
\hline
\end{tabular}

Note: Values shown are the mean \pm standard deviation

From Table 2, it can be seen that P2T and P3T reveal similar values of caliper, grammage, and stiffness $(D)$, although P3T was slightly thicker (30 $\mu \mathrm{m}$ more), and had a slightly lower grammage and stiffness (higher value of $D$ indicates lower stiffness) than P2T. Regarding the other two parameters, TS7 and TS750, they are both higher for both surfaces of P3T comparatively to P2T, especially for its bottom surface. Higher values for these two parameters indicate lower surface softness and lower smoothness, respectively, being concordant with the HF values presented in Table 1.

At continuation, a second experiment was conducted considering now the 4 possible assembled configurations $\mathrm{T} / \mathrm{B}, \mathrm{T} / \mathrm{T}, \mathrm{B} / \mathrm{B}$, and $\mathrm{B} / \mathrm{T}$ used for production of $\mathrm{P} 2 \mathrm{~T}$ and P3T.

\section{Experiment $B$ - TSA Measurements of the Arranged Configurations T/B, $T / T, B / B$ and $B / T$}

The HF for the assembled configurations $\mathrm{T} / \mathrm{B}, \mathrm{T} / \mathrm{T}, \mathrm{B} / \mathrm{B}$, and $\mathrm{B} / \mathrm{T}$ are shown in Table 3.

Table 3. HF for the 4 Assembled Configurations $T / B, T / T, B / B$, and $B / T$

\begin{tabular}{|c|c|c|c|}
\hline Configuration & Top Surface HF & Bottom Surface HF & Global HF \\
\hline T/B & $76.8 \pm 0.6$ & $78.0 \pm 2.1$ & $77.4 \pm 1.6$ \\
\hline T/T & $77.6 \pm 1.7$ & $79.8 \pm 0.7$ & $78.7 \pm 1.7$ \\
\hline B/B & $78.6 \pm 0.9$ & $80.1 \pm 1.1$ & $79.4 \pm 1.2$ \\
\hline B/T & $79.1 \pm 1.7$ & $79.3 \pm 2.6$ & $79.2 \pm 2.1$ \\
\hline
\end{tabular}

Note: Values shown are the mean \pm standard deviation

From Table 3, only small variations of HF were noted for the four assembled configurations $\mathrm{T} / \mathrm{B}, \mathrm{T} / \mathrm{T}, \mathrm{B} / \mathrm{B}$, and $\mathrm{B} / \mathrm{T}$. After analyzing the results of each configuration, the maximum difference registered between the top and bottom surfaces was $2.2 \mathrm{HF}$ units associated to the configuration $\mathrm{T} / \mathrm{T}$, which was very far from the $10.3 \mathrm{HF}$ units registered for the product P3T in the previous experiment. The minimum difference registered from top to bottom was $0.2 \mathrm{HF}$ units associated to the configuration $\mathrm{B} / \mathrm{T}$. The maximum difference registered between configurations was $2.3 \mathrm{HF}$ units on the top surface and 2.1 $\mathrm{HF}$ units on the bottom surface. To further explore the four assembled configurations, their values of caliper (thickness), grammage, and of the remaining parameters measured by the TSA were also considered (Table 4). 
Table 4. Caliper, Grammage, TS7, TS750, and $D$ for the Four Assembled Configurations $\mathrm{T} / \mathrm{B}, \mathrm{T} / \mathrm{T}, \mathrm{B} / \mathrm{B}$, and $\mathrm{B} / \mathrm{T}$

\begin{tabular}{|c|c|c|c|c|c|c|}
\hline Configuration & Surface & Caliper $(\boldsymbol{\mu m})$ & $\begin{array}{c}\text { Grammage } \\
\left(\mathbf{g} / \mathbf{m}^{2}\right)\end{array}$ & TS7 & TS750 & $\boldsymbol{D}(\mathbf{m m} / \mathbf{N})$ \\
\hline \multirow{3}{*}{ T/B } & Top & - & - & $13.9 \pm 0.4$ & $35.5 \pm 1.3$ & $1.5 \pm 0.0$ \\
\cline { 2 - 7 } & Bottom & - & - & $13.5 \pm 1.1$ & $26.4 \pm 2.5$ & $1.5 \pm 0.0$ \\
\cline { 2 - 7 } & Global & $497 \pm 4$ & $79.0 \pm 1.1$ & $13.7 \pm 0.8$ & $31.0 \pm 5.2$ & $1.5 \pm 0.0$ \\
\hline \multirow{3}{*}{ T/T } & Top & - & - & $13.7 \pm 1.0$ & $31.3 \pm 1.0$ & $1.5 \pm 0.0$ \\
\cline { 2 - 7 } & Bottom & - & - & $12.6 \pm 0.4$ & $24.0 \pm 3.0$ & $1.5 \pm 0.0$ \\
\cline { 2 - 7 } & Global & $495 \pm 3$ & $79.0 \pm 1.1$ & $13.1 \pm 0.9$ & $27.7 \pm 4.4$ & $1.5 \pm 0.0$ \\
\hline \multirow{3}{*}{ B/B } & Top & - & - & $13.1 \pm 0.5$ & $28.1 \pm 1.7$ & $1.5 \pm 0.0$ \\
\cline { 2 - 7 } & Bottom & - & - & $12.3 \pm 0.6$ & $27.2 \pm 1.4$ & $1.5 \pm 0.0$ \\
\cline { 2 - 7 } & Global & $496 \pm 5$ & $79.0 \pm 1.1$ & $12.7 \pm 0.7$ & $27.7 \pm 1.6$ & $1.5 \pm 0.0$ \\
\hline \multirow{3}{*}{ B/T } & Top & - & - & $12.9 \pm 1.0$ & $26.3 \pm 2.0$ & $1.5 \pm 0.0$ \\
\cline { 2 - 7 } & Bottom & - & - & $12.9 \pm 1.4$ & $22.6 \pm 1.1$ & $1.5 \pm 0.0$ \\
\cline { 2 - 7 } & Global & $495 \pm 6$ & $79.0 \pm 1.1$ & $12.9 \pm 1.1$ & $24.5 \pm 2.5$ & $1.5 \pm 0.0$ \\
\hline
\end{tabular}

Note: Values shown are the mean \pm standard deviation

From Table 4, it can be seen that all four assembled configurations had the same grammage and stiffness $(D)$ and had practically the same caliper. A special remark must be made to the lower caliper of the four assembled configurations comparatively to the finished products P2T and P3T, and also of their higher stiffness, both of them caused by the absence of embossing. The embossing operation usually increases the caliper and decreases the stiffness of the samples. Regarding the other two parameters, TS7 and TS750, they revealed fluctuations for the four assembled configurations. However, were shown to be concordant with the HF values, that is, higher HF values were globally associated with lower values of TS7 and TS750, whereas lower HF values were globally associated with higher values of TS7 and TS750.

Overall, this experiment showed two different things. First, the HF values presented in Table 3 only reveal small variations for the four assembled configurations. Therefore, whether the surfaces of the mother-reels are positioned inwards or outwards in the final configurations does not seem to be a crucial point that justifies the detected decrease in HF registered in the previous experiment. This can also be confirmed from the other parameters measured for the four assembled configurations presented in Table 4. There are cases in which relevant differences can be noted in softness on both surfaces of a motherreel and therefore, how the mother-reel is positioned in the finished product can be a very relevant point. However, that is not what happened in this case since the tested surfaces were all very similar with analogous characteristics.

Second, the HF values obtained in the four assembled configurations are higher than those obtained in the two products P2T and P3T. This means that converting had a negative effect on the softness values, however, to different extents. Product P2T only showed a slight decrease in HF compared to the assembled configurations. Regarding product P3T, its top surface also suffered only a slight decrease in HF in comparison to the assembled configurations, although higher than P2T. The huge difference in HF, which deserved our attention, was clearly associated with the bottom surface of the product P3T. Once again, this can be confirmed from the other parameters measured for the four assembled configurations presented in Table 4. In particular, although some differences can be identified in the values of the parameters TS7 and $D$ for the four assembled configurations comparatively to the finished products, it was the TS750 parameter that 
revealed very large differences in the values obtained for the four assembled configurations in comparison to the finished products, this parameter being related with the surface geometry and with the embossing process.

In such way, this experiment strongly supports that the differences noted in softness, between products P2T and P3T, were generated in the converting process. Therefore, the next step will be to investigate what happens in the converting line. What exactly causes the considerable difference in HF between the top and bottom surfaces of product P3T? To further explore this question, a third experiment was conducted using the optical system for observation of the products surfaces of P2T and P3T and identify possible differences that might explain their distinct behaviors.

\section{Experiment C - Image Analysis of the Products P2T and P3T}

In this last experiment, both products P2T and P3T were analyzed using a customized optical system (Mendes et al. 2013, 2014, 2015). For the two products P2T and P3T, a set of 8 images was registered.
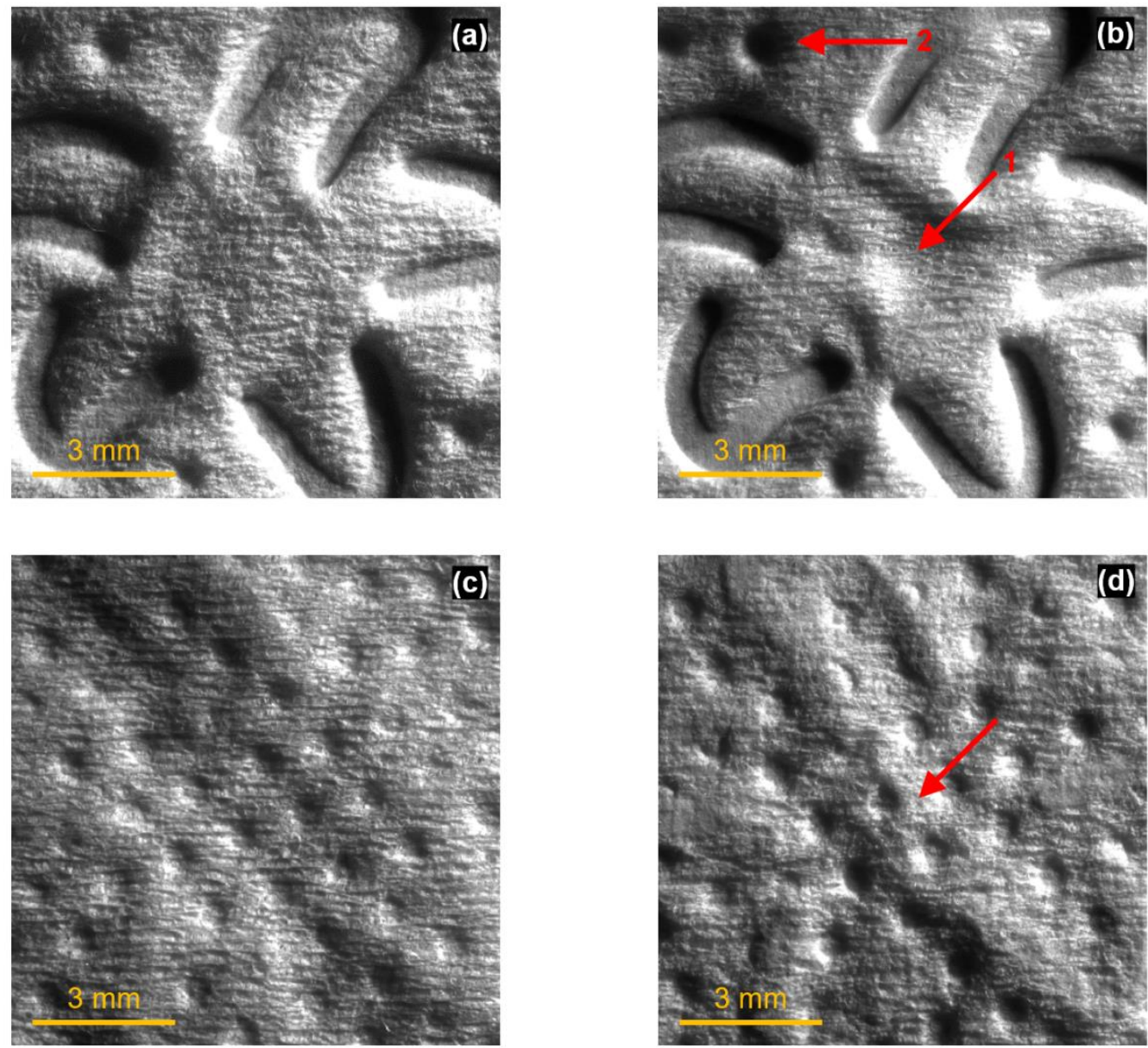

Fig. 4. Images of the embossed patterns engraved on the products a) star on top surface of P2T, b) star on top surface of P3T, c) small holes on bottom surface of P2T, and d) small holes on bottom surface of P3T. The images of $c$ ) and d), area $\mathrm{ME}_{1}$ were captured in the same exact location of the images of $a$ ) and b), area $D E_{1}$, but seen from the opposite side of the papers (size of images $\approx 10 \times 10 \mathrm{~mm}^{2}$ ). 

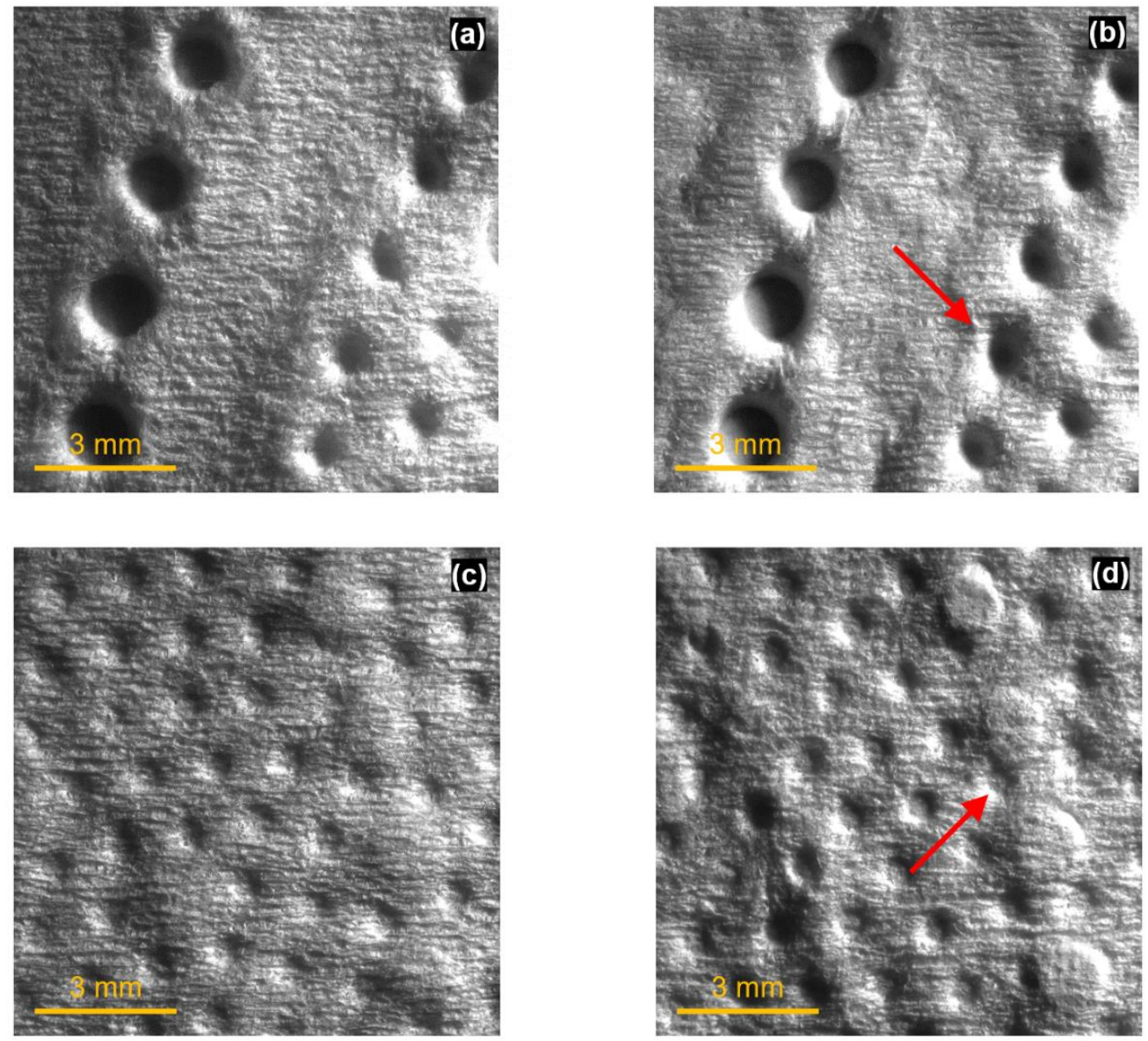

Fig. 5. Images of the embossed patterns engraved on the products a) deep holes on top surface of P2T, b) deep holes on top surface of P3T, c) small holes on bottom surface of P2T, and d) small holes on bottom surface of P3T. The images of $\mathrm{c}$ ) and d), area $\mathrm{ME}_{2}$, were captured in the same exact location of the images of a) and b), area $D E_{2}$, but seen from the opposite side of the papers (size of images $\approx 10 \times 10 \mathrm{~mm}^{2}$ ).

The images correspond to distinct areas of the "deco" (top surface) and "micro" (bottom surface) embossing drawings that were engraved on P2T and P3T at the converting line. The "deco" embossing shown in the images is composed of a star (area DE 1 ) and a pattern of deep holes (area $\mathrm{DE}_{2}$ ). The "micro" embossing shown in the images is composed of a grid of small holes in the place where the star was engraved (area $\mathrm{ME}_{1}$ ) and where the deep holes were engraved (area $\mathrm{ME}_{2}$ ). The images in Fig. 4 and Fig. 5 correspond to these drawings' areas as seen from the corresponding top and bottom surfaces on both products.

Several interesting conclusions were made for both products. As shown in Fig. 4 a) and b), the top surface of P2T shows a flatter area for the embossed star, whereas P3T shows a curlier area for the same drawing (see red arrow 1 in Fig. 4 b). In addition, some details of the "deco" embossing appear to be a little deeper in PT3 than in PT2 (see red arrow 2 in Fig. 4 b). From Fig. 5 a) and b), the top surfaces of P2T and P3T show the pattern of deep holes embossed with practically the same aspect, but also some details of the "deco" embossing appeared to be deeper in PT3 than in PT2 (see red arrow in Fig. 5 b indicating the 5 holes located in the right inferior quadrant of the image). These observations are consistent with the similar values of HF on the top surfaces of P2T and P3T. Although, a slight decrease of HF was noted on P3T comparatively to P2T, the deeper 
details do not affect seriously the top surfaces of the product.

Some differences were identified on the bottom surfaces of the products P2T and P3T. As shown in Fig. 4 and 5 c) and d), the grid of small holes embossed directly in the bottom surfaces of P2T and P3T is similar for both cases, yet slightly more pronounced in P3T than in P2T. However, the considerable difference between P2T and P3T lies in the "deco" engravings of P3T being seen more prominently from the bottom surface, comparatively to P2T. In Fig. $4 \mathrm{c}$ ) a slight curvature is noticed in P2T on the location on which the embossed star was engraved, whereas in Fig. 4 d) well defined marks coincident with the limits of the embossed star are easily noticed in P3T (see red arrow in Fig. $4 \mathrm{~d}$ ). In Fig. 5 c) and d) the limits of the embossed pattern of deep holes are barely noticed in P2T, whereas in P3T they are a lot more pronounced and their limits are easily identified in the image (see red arrow in Fig. 5 d). In such way, the observations made for the bottom surfaces of the products P2T and P3T appear to be consistent with the results of HF which revealed a huge drop for the bottom surface of the product P3T comparatively to $\mathrm{P} 2 \mathrm{~T}$.

Having in consideration these observations, the same question raised earlier can still be posed. Why do the products P2T and P3T have such different bottom surfaces? The answer is actually simple. In the converting line, the mother-reel placed on top is embossed with the "deco engravings" whereas the mother-reel placed on the bottom is embossed with the "micro engravings". The two mother-reels are then subjected to a last operation that joins together the entire set of tissue sheets (ply bonding). In the case of the two products addressed in this work, more pressure was applied in the "deco" embossing of P3T $\approx 38$ to $40 \mathrm{~kg} / \mathrm{cm}$ ) than in $\mathrm{P} 2 \mathrm{~T}(\approx 20$ to $30 \mathrm{~kg} / \mathrm{cm})$. This additional pressure resulted in the curlier star, the more pronounced pattern of deep holes, and in the deeper details engraved in the top surface of P3T relatively to P2T, as can be seen in Fig. 4 and 5 a) and b). This also resulted in the "deco engravings" of P3T being more prominent from the opposite side comparatively to $\mathrm{P} 2 \mathrm{~T}$.

When the top surface of the products is under evaluation, either by an equipment or by touch, the "deco engravings" in its surface are perceived as depressions, and therefore, neither the equipment nor the consumer will notice them very negatively, since they do not affect considerably the global touch of the surface. The "micro engravings" in the bottom surface are not prominent, therefore not perceived on the top surface of the products, and also do not affect the top surface results. However, when the bottom surface of the products is being evaluated, the case differs. The "micro engravings" are not noticed overly by the equipment or by touch on the bottom surfaces, since the product P2T shows a softness comparable to that obtained in the top surfaces of P2T and P3T, suggesting that it has little effect on softness. In both products, similar values of pressure were applied in the "micro" embossing ( $\approx 20$ to $30 \mathrm{~kg} / \mathrm{cm})$. However, a second effect happened in this case. The "deco" embossing drawings perceived as depressions in the top surfaces, were perceived as elevations from the other side. In such way, these embossed drawings were seen and felt from the bottom surface of the products. Notably, because the product P2T has the 3-ply mother-reel (M3) on bottom, it has an additional tissue sheet functioning as a protection minimizing the effect of the "deco" embossing on the bottom surface of P2T. On the other hand, the product P3T has the 2-ply mother-reel (M2) on the bottom, meaning that the additional sheet is not present in this case, leaving its bottom surface more exposed to the "deco" embossing. Therefore, this will result exactly in what was registered and seen through the performed experiments presented in this work, an overall softer and more pleasant to touch product P2T, and an overall rougher and less pleasant product P3T. 


\section{CONCLUSIONS}

1. Two objective methodologies were used in this work to perform a complete analysis of two 5-ply finished tissue products for their softness and surface characterization. Both products were composed by the same base tissue papers, but with some changes made in their converting conditions.

2. The bottom surface of P3T exhibited the lowest softness. The remaining three surfaces, both tops of P2T and P3T and bottom of P2T, revealed similar values of softness.

3. The customized optical system enabled, through image analysis, the identification in both products of the causes behind the obtained differences in softness. In particular, it was found that the "deco" embossing was seen and felt differently in the bottom surface of both products. This occurrence depended on the embossing pressure and on the number of plies present in the bottom surface.

4. For this particular case, having the 2-ply mother-reel (M2) placed on top and the 3-ply mother-reel (M3) placed on bottom, instead of the other way around, and with lower pressure used to engrave the "deco" embossing drawings, resulted in a finished product with better overall performance in terms of softness. It is true that if only the top surface of the end-use products is assessed, the differences between products are not very relevant. However, if the products are analyzed as a whole, assessing both surfaces of the products, the differences between both products are relevant, and the product P2T is more pleasant to touch, having a better softness quality than the product P3T.

\section{ACKNOWLEDGMENTS}

The authors gratefully acknowledge the funding of this work that was carried out under the Project InPaCTus - Innovative Products and Technologies from Eucalyptus, Project N 21874 funded by Portugal 2020 through European Regional Development Fund (ERDF) in the frame of COMPETE $2020 \mathrm{n}^{\circ}$ 246/AXIS II/2017. The authors are also thankful for financial support from the Fiber Materials and Environmental Technologies (FibEnTech-UBI) research unit of the Universidade da Beira Interior on extent of the project UIDB/00195/2020. Finally, the authors acknowledge the materials, access to equipment and installations, and all the general support given by The Navigator Company, RAIZ, and the Optical Center, Department of Physics, Department of Textile Science and Technology, and Department of Chemistry of the Universidade da Beira Interior.

\section{REFERENCES CITED}

Abbott, J. C., and Schnabel, K. (2000). "Hygiene papers," in: Papermaking Science and Technology, Book 17 - Pulp and Paper Testing, J. E. Levlin, and L. Söderhjelm (eds.), Finnish Paper Engineers' Association and TAPPI, Helsinki, Chapter 11.

Anukul, P., Khantayanuwong, S., and Somboon, P. (2015). "Development of laboratory wet creping method to evaluate and control pulp quality for tissue," TAPPI Journal 14(5), 339-345. DOI: 10.32964/TJ14.5.339

Boudreau, J., and Germgård, U. (2014). "Influence of various pulp properties on the 
adhesion between tissue paper and Yankee cylinder surface," BioResources 9(2), 2107-2114. DOI: 10.15376/biores.9.2.2107-2114

de Assis, T., Reisinger, L. W., Pal, L., Pawlak, J., Jameel, H., and Gonzalez, R. W. (2018a). "Understanding the effect of machine technology and cellulosic fibers on tissue properties - A review," BioResources 13(2), 4593-4629. DOI:

10.15376/biores.13.2.4593-4629

de Assis, T., Reisinger, L. W., Dasmohapatra, S., Pawlak, J., Jameel, H., Pal, L., Kavalew, D., and Gonzalez, R. W. (2018b). "Performance and sustainability vs. the shelf price of tissue paper kitchen towels," BioResources 13(3), 6868-6892. DOI: 10.15376/biores.13.3.6868-6892

EMTEC Innovative Testing Solutions (2018). “TSA - Tissue softness analyzer," (https://www.emtec-electronic.de/en/tsa-tissue-softness-analyzer.html), Accessed on June 7, 2018.

Furman, G., de Roever, E., Frette, G., and Gomez, S. (2007). "Analysis of the surface softness of tissue paper using confocal laser scanning microscopy," in: Proceedings of Tissue World 2007 Conference, Nice, France, pp. 1-10.

Gigac, J., and Fišerová, M. (2008). "Influence of pulp refining on tissue paper properties," TAPPI Journal 7(8), 27-32.

Ho, J., Hutton, B. F., Proctor, J., and Batchelor, W. (2007). "Development of a tissue creping test rig," in: Proc. CHEMECA 2007, Melbourne, Australia, pp. 1326-1332.

Hollmark, H. (1983). "Mechanical properties of tissue," in: Handbook of Physical and Mechanical Testing of Paper and Paperboard, Vol. 1., R. E. Mark (ed.), Dekker, New York.

Hollmark, H., and Ampulski, R.S. (2004). "Measurement of tissue paper softness: A literature review," Nordic Pulp \& Paper Research Journal 19(3), 345-353. DOI: 10.3183/npprj-2004-19-03-p345-353

ISO 12625-3 (2014). “Tissue paper and tissue products - Part 3: Determination of thickness, bulking thickness and apparent bulk density and bulk," International Organization for Standardization, Geneva, Switzerland.

ISO 12625-6 (2005). "Tissue paper and tissue products - Part 6: Determination of grammage," International Organization for Standardization, Geneva, Switzerland.

Kimari, O. (2000). "Chapter 3 - Tissue" in: Papermaking Science and Technology, Book 18 - Paper and board grades. H. Paulapuro (ed.), Finnish Paper Engineers' Association and TAPPI, Helsinki.

Ko, Y. C., Park, J. Y., Melani, L., Park, N. Y., and Kim, H-J. (2018). "Principles of developing physical test methods for disposable consumer products," Nordic Pulp \& Paper Research Journal 34(1), 75-87. DOI: 10.1515/npprj-2018-0029

Lima, M., Silva, L. F., Vasconcelos, R., and Carneiro, A. (2009). "FRICTORQ, Mechatonic design for the objective measurement of friction in 2D soft surfaces," in: Proceedings of MECAHITECH'09, Bucharest, Romania, pp. 144-153.

Mendes, A. O., Fiadeiro, P. T., Costa, A. P., Amaral, M. E., and Belgacem, M. N. (2013). "Retro-diffusion and transmission of laser radiation to characterize the paper fiber distribution and mass density," in: Proceedings of SPIE 8785, Porto, Portugal, 8785AY-1/8785AY-8. DOI: 10.1117/12.2022367

Mendes, A. O., Fiadeiro, P. T., Costa, A. P., Amaral, M. E., and Belgacem, M. N. (2014). "Study of repeatability of an optical laser system for characterization of the paper fiber distribution and mass density," in: Proceedings of SPIE 9286, Aveiro, Portugal, 92862Y-1/92862Y-8. DOI: 10.1117/12.2062697 
Mendes, A. O., Fiadeiro, P. T., Costa, A. P., Amaral, M. E., and Belgacem, M. N. (2015). "Laser scanning for assessment of the fiber anisotropy and orientation in the surfaces and bulk of the paper," Nordic Pulp \& Paper Research Journal 30(2), 308-318. DOI: 10.3183/npprj-2015-30-02-p308-318

Perng, Y. S., Teng, T. Y., and Chang, C. H. (2019). "A study of the softness of household tissues using a tissue softness analyzer and hand-felt panels," TAPPI Journal 18(3), 195-209. DOI: 10.32964/TJ18.3.195

Ramasubramanian, M. K., and Shmagin, D. L. (2000). "An experimental investigation of the creping process in low-density paper manufacturing," Journal of Manufacturing Science and Engineering 122(3), 576-581. DOI: 10.1115/1.1285908

Ramasubramanian, M. K., Sun, Z., and Gupta, S. (2011). "Modeling and simulation of the creping process," in: PaperCon 2011 Vol 1, Covington, USA, pp. 576-582.

Rastogi, V. K., Grossmann, H., Ray, A. K., and Greiffenberg, I. (2017). "Dependence of softness perception on tissue physical properties and development of neural model for predicting softness," IPPTA - The official International Journal, 29(2), 128-135.

Raunio, J. P., and Ritala, R. (2012). "Simulation of creping pattern in tissue paper," Nordic Pulp \& Paper Research Journal 27(2), 375-381. DOI: 10.3183/npprj-201227-02-p375-381

Raunio, J. P., Löyttyniemi T., and Ritala, R. (2018). "Online quality evaluation of tissue paper structure on new generation tissue machines," Nordic Pulp \& Paper Research Journal 33(1), 133-141. DOI: 10.1515/npprj-2018-3004

Rosen, B-G., Fall, A., Rosen, S., Farbrot, A., and Bergström, P. (2014). “Topographic modelling of haptic properties of tissue products," in: Journal of Physics: Conference Series 483(012010), Taipei, Taiwan, pp. 1-6. DOI: 10.1088/1742-6596/483/1/012010

Ruiz, J., Sacon, V. M., Pescatori Silva, F. H., Eichhorn, S., Bley, L., Sabel, H., Villette, M. J., Eymin Petot-Tourtollet, G., and Petit-Conil, M. (2010). "Tissue softness potential: An objective online industrial value," ATIP 64(3), 10-15.

Rust, J. P., Keadle, T. L., Allen, D. B., Shalev, I., and Barker, R. L. (1994). "Tissue softness evaluation by mechanical stylus scanning," Textile Research Journal 64(3), 163-168. DOI: 10.1177/004051759406400306

Spina, R., and Cavalcante, B. (2018). "Characterizing materials and processes used on paper tissue converting lines," Materials Today Communications 17, 427-437. DOI: 10.1016/j.mtcomm.2018.10.006

Vieira, J. C., Mendes, A. O., Carta, A. M., Galli, E., Fiadeiro, P. T., and Costa, A. P. (2020). "Impact of embossing on liquid absorption of toilet tissue papers," BioResources 15(2), 3888-3898. DOI: 10.15376/biores.15.2.3888-3898

Wang, Y., de Assis, T., Zambrano, F., Pal, L., Venditti, R., Dasmohapatra, S., Pawlak, J., and Gonzalez, R. (2019). "Relationship between human perception of softness and instrument measurements," BioResources 14(1), 780-795. DOI:

10.15376/biores.14.1.780-795

Article submitted: May 17, 2020; Peer review completed: July 3, 2020; Revised version received and accepted: July 28, 2020; Published: July 31, 2020.

DOI: $10.15376 /$ biores. 15.3.7178-7190

ERRATUM: August 11, 2020: The value in Table 4 was changed from $76.4 \pm 0.5$ to

$79.0 \pm 1.1$. This edit does not change the conclusions of the paper. 